\title{
Bis-1,3-dithiolium Salts as Initiators for the Cationic Polymerization of Vinyl Monomers
}

\author{
Eri YosHIDA
}

Department of Polymer Science and Engineering, Kyoto Institute of Technology,

Goshokaido-cho, Matsugasaki, Sakyo-ku, Kyoto 606, Japan

(Received April 10, 1996)

KEY WORDS Bis-1,3-dithiolium Salts / Radical Cation / Cationic Polymerization / Initiator / Vinyl

Monomers /

Bis-1,3-dithiolium salt (1) derived from tetrathiafulvalene (TTF, 2), is a stable radical cation and forms the following reversible redox system.<smiles>C1=CSC(=C2SC=CS2)S1</smiles>

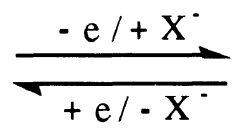<smiles>[X]C1=CSC(=C2SC=CS2)S1</smiles>

2<smiles>[Y][Z]1=CSC(=C2SC=CS2)S1</smiles>

1 has been reported to be important as an excellent organic solid-state semiconductor. ${ }^{1}$ Radical cation salts show metallic behavior around room temperature as derivatives from tetramethylated-TTF and have $\mathrm{BF}_{4}{ }^{-}$, $\mathrm{ClO}_{4}{ }^{-}$, or $\mathrm{PF}_{6}{ }^{-}$as a counter anion. ${ }^{2}$ In spite of the fact that 1 has the property of receiving and/or donating electrons easily, there is no report on organic synthesis using 1. It is possible that 1 has potential as an initiator not only for cationic, but also for anionic polymerization if 1 can receive an electron from electron-rich vinyl monomers and/or donate an electron to electron-poor ones. A radical cation of anthracene generated by the reaction of anthracene with oxygen in sulfur dioxide, can initiate the cationic polymerization of styrene. ${ }^{3}$ However, this radical cation is not stable enough to be isolated. I recently reported a convenient method for synthesis of 1, in high yield, with some anions by the selective one-electron oxidation of TTF. ${ }^{4}$ In this paper, the application of $\mathbf{1}$ to an initiator for cationic polymerization of electron-rich vinyl monomers is described.

For initiation by $\mathbf{1}$, two mechanisms can be proposed: coupling of the radicals of vinyl monomer generated by one-electron transfer from the monomer to 1 (Scheme 1, path a) and direct electrophilic attack of $\mathbf{1}$ on the vinyl group of the monomer (path b). It may be expected that the polymer obtained will have a TTF moiety at its head group, if polymerization proceeds in accordance with the second mechanism.

\section{EXPERIMENTAL}

\section{Measurements}

Gel permeation chromatography (GPC) was performed with a Tosoh HLC-802A (eluent; THF, $40^{\circ} \mathrm{C}$, $1.0 \mathrm{ml} \mathrm{min}^{-1}$, columns; polystyrene gels $\left(\mathrm{G} 4000 \mathrm{H}_{8}\right.$ and $\mathrm{G} 2000 \mathrm{H}_{8}$ ), calibration; standard polystyrenes). Gas

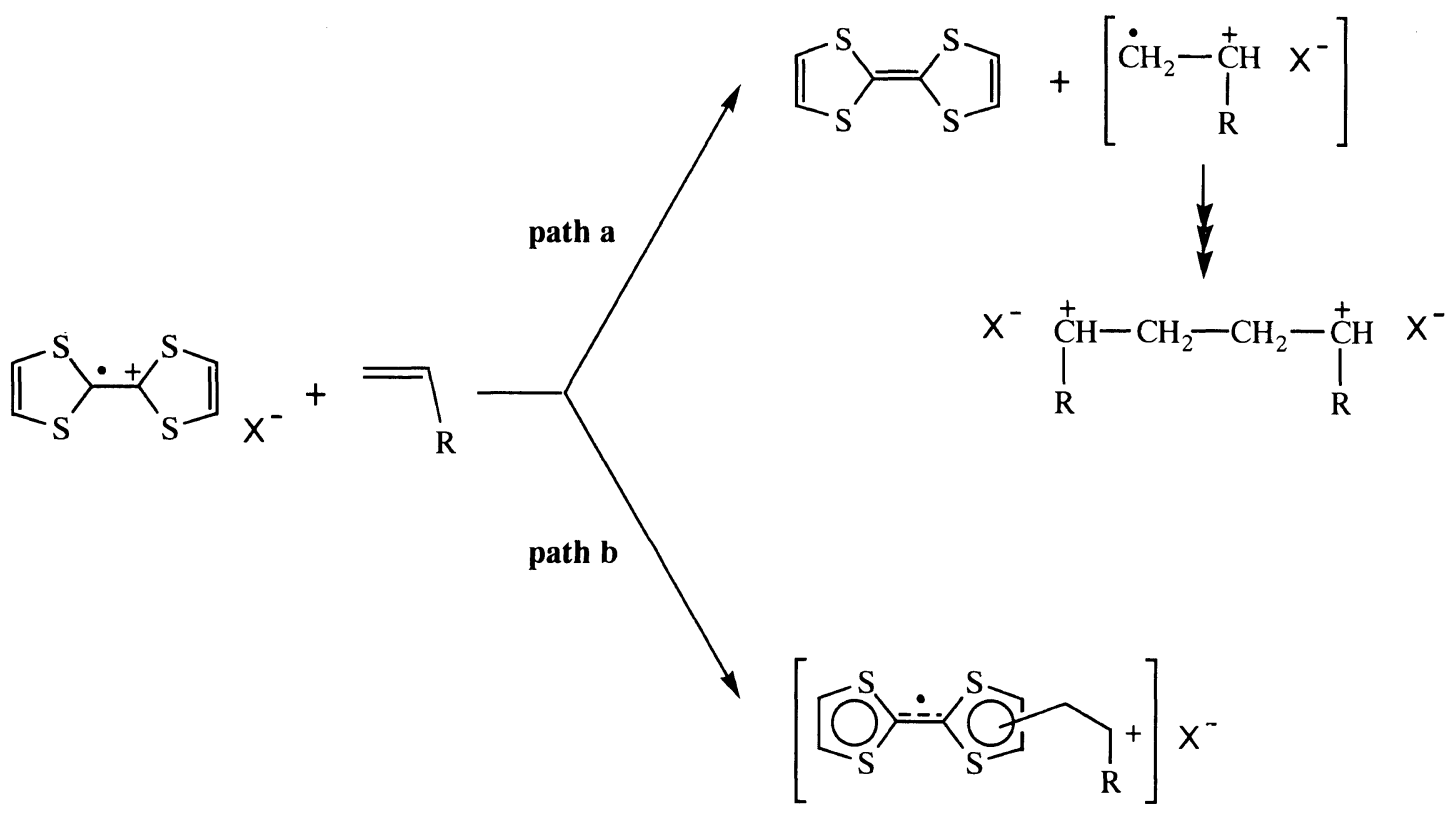

Scheme 1. 
chromatography (GC) was performed with a Shimadzu GC-8A. UV spectra were recorded on a Beckman DU-68 spectrophotometer.

\section{Materials}

Bis-1,3-dithiolium chloride $\left(3, \mathrm{X}^{-}=\mathrm{Cl}^{-}\right)$, nitrate $(\mathbf{4}$, $\left.\mathrm{X}^{-}=\mathrm{NO}_{3}{ }^{-}\right)$, tetrafluoroborate $\left(5, \mathrm{X}^{-}=\mathrm{BF}_{4}{ }^{-}\right)$, perchlorate $\left(6, \mathrm{X}^{-}=\mathrm{ClO}_{4}{ }^{-}\right)$, and hexafluoroantimonate (7, $\left.\mathrm{X}^{-}=\mathrm{SbF}_{6}{ }^{-}\right)$were prepared by the method reported previously. ${ }^{4}$ Commercial grade isobutyl vinyl ether, ethyl vinyl ether, and 2,3-dihydrofuran were distilled twice over sodium before use. $p$-Methoxystyrene and styrene were washed with aqueous alkaline solution and water, and distilled over calcium hydride. $N$-Vinylcarbazole was recrystallized from methanol. Nitrobenzene, dichloromethane, and nitromethane were purified and distilled in the usual manner.

\section{Cationic Polymerization with Bis-1,3-dithiolium Salts: General Procedure}

Polymerization was carried out at $0-30^{\circ} \mathrm{C}$ under a dry nitrogen atmosphere in a baked flask with a threeway stopcock. To a solution of $7(21 \mathrm{mg} ; 0.0477 \mathrm{mmol})$ in $5 \mathrm{ml}$ of nitrobenzene, $0.65 \mathrm{ml}$ of IBVE was added at $30^{\circ} \mathrm{C}$. The mixture was vigorously stirred and kept at $30^{\circ} \mathrm{C}$ for $24 \mathrm{~h}$. The polymerization was quenched by adding ammoniacal methanol and washed with water, evaporated under reduced pressure, and dried in vacuo for several hours to give the product polymer. Conversion of IBVE was estimated by gas chromatography (GC) of the mixture after addition of toluene as the internal standard.

\section{RESULTS AND DISCUSSION}

Cationic polymerization of IBVE was carried out in nitrobenzene at $30^{\circ} \mathrm{C}$ for $24 \mathrm{~h}$ with five 1 initiators: bis-1,3-dithiolium chloride $\left(3, \mathrm{X}^{-}=\mathrm{Cl}^{-}\right)$, nitrate $(4$, $\left.\mathrm{X}^{-}=\mathrm{NO}_{3}{ }^{-}\right)$, tetrafluoroborate $\left(5, \mathrm{X}^{-}=\mathrm{BF}_{4}{ }^{-}\right)$, perchlorate $\left(6, \mathrm{X}^{-}=\mathrm{ClO}_{4}^{-}\right)$, and hexafluoroantimonate $(7$, $\left.\mathrm{X}^{-}=\mathrm{SbF}_{6}{ }^{-}\right)$. The results are shown in Table I.

No polymerization proceeded with 3 . 4 initiated the polymerization to give the corresponding oligomer. 5, 6, and 7 polymerized IBVE to give polymers with high

Table I. Polymerization of IBVE initiated with bis-1,3-dithiolium salts ${ }^{\mathrm{a}}$

\begin{tabular}{|c|c|c|c|c|c|}
\hline $\mathrm{X}^{-}$ & $\begin{array}{c}\text { Compound } \\
\text { No. }\end{array}$ & Solvent & $\frac{\text { Conversion }^{\mathrm{b}}}{\%}$ & $M_{n}^{\mathrm{c}}$ & $M_{w} / M_{n}^{\mathrm{c}}$ \\
\hline $\mathrm{Cl}^{-}$ & 3 & $\mathrm{PhNO}_{2}$ & 0 & $\ldots{ }^{d}$ & $-^{\mathrm{d}}$ \\
\hline $\mathrm{NO}_{3}{ }^{-}$ & 4 & $\mathrm{PhNO}_{2}$ & 84 & 2500 & 1.84 \\
\hline $\mathrm{BF}_{4}^{-}$ & 5 & $\mathrm{PhNO}_{2}$ & 89 & 31000 & 2.26 \\
\hline $\mathrm{ClO}_{4}{ }^{-}$ & 6 & $\mathrm{PhNO}_{2}$ & 99 & 21000 & 2.64 \\
\hline $\mathrm{SbF}_{6}{ }^{-}$ & 7 & $\mathrm{PhNO}_{2}$ & 100 & 16000 & 2.30 \\
\hline $\mathrm{SbF}_{6}{ }^{-}$ & 7 & $\mathrm{PhNO}_{2}{ }^{\mathrm{e}}$ & 90 & $\simeq^{d}$ & $\sim^{\mathrm{d}}$ \\
\hline $\mathrm{SbF}_{6}{ }^{-}$ & 7 & $\mathrm{f}^{\mathrm{f}}$ & 99 & 18000 & 2.80 \\
\hline $\mathrm{SbF}_{6}{ }^{-}$ & 7 & $\mathrm{CH}_{3} \mathrm{NO}_{2}$ & 94 & 9300 & 2.91 \\
\hline $\mathrm{SbF}_{6}{ }^{-}$ & 7 & $\mathrm{CH}_{2} \mathrm{Cl}_{2}$ & 96 & 8800 & 2.37 \\
\hline
\end{tabular}

${ }^{\mathrm{a}}[\mathrm{IBVE}]_{0}=1 \mathrm{M}$, [Initiator $]_{0}=10 \mathrm{mM}$, at $30^{\circ} \mathrm{C}$ for $24 \mathrm{~h} .{ }^{\mathrm{b}} \mathrm{Calcu}-$ lated by GC. ${ }^{\mathrm{c}}$ Estimated by GPC based on PSt standards. ${ }^{\mathrm{d}}$ Could not be determined. ${ }^{\mathrm{e}}$ Polymerized at $60^{\circ} \mathrm{C}$. ${ }^{\mathrm{f}}$ Polymerized in bulk at $60^{\circ} \mathrm{C}$. molecular weights. The conversion of IBVE was achieved at $100 \%$ in the case of 7 . When polymerization with 7 was carried out in nitrobenzene at $60^{\circ} \mathrm{C}$, the product was insoluble in all the common organic solvents used, but swelled in dichloromethane, while bulk polymerization of IBVE was performed by 7 at $60^{\circ} \mathrm{C}$ for $24 \mathrm{~h}$ to give the soluble corresponding polymer. This suggests that an intermolecular reaction occurs in nitrobenzene at $60^{\circ} \mathrm{C}$ between the carbocationic growing end and oxygen of the side chain, due to the high polarity of the solvent, resulting in the formation of crosslinking. The polymerization of IBVE with 7 was performed in various solvents. The number average molecular weight increased with solvent polarity. The polymerization rate also increased with solvent polarity, as shown in Figure 1.

Figure 2 shows plots of average molecular weight and polydispersity versus conversion, for the polymerization of IBVE initiated by 7 in dichloromethane at $30^{\circ} \mathrm{C}$. The propagation appeared much faster than the initiation because a high molecular weight polymer $\left(M_{n}=13000\right)$ was formed at conversion of only $39 \%$.

Figure 3 illustrates temperature-conversion plots for the polymerization of IBVE initiated by 7 in nitrobenzene for $6 \mathrm{~h}$. The polymerization hardly proceeded below $0^{\circ} \mathrm{C}$ but started to take place above $0^{\circ} \mathrm{C}$. Polymerization was highly dependent on temperature because conversion was only $43 \%$ at $0^{\circ} \mathrm{C}$ in polymerization by 7 , while polymerization quantitatively proceeded with oxoaminium hexafluoroantimonate at the same temperature. ${ }^{5}$

The cationic polymerization of several vinyl monomers with $7(1 \mathrm{~mol} \%)$ was carried out at $30^{\circ} \mathrm{C}$ for 2 days in nitrobenzene, or in a mixture of nitrobenzene and dichloromethane. The results are shown in Table II.

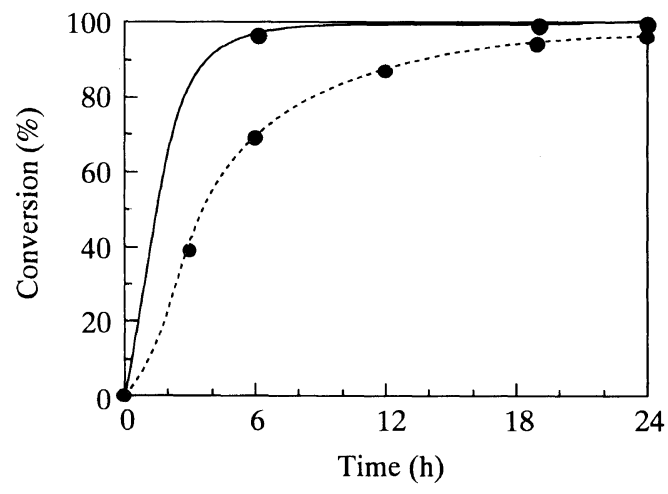

Figure 1. Time-conversion curves for the polymerization of IBVE with 7 in nitrobenzene (solid line) and dichloromethane (broken line): $[\mathrm{IBVE}]_{0}=1 \mathrm{M} ;[7]_{0}=10 \mathrm{mM}$.

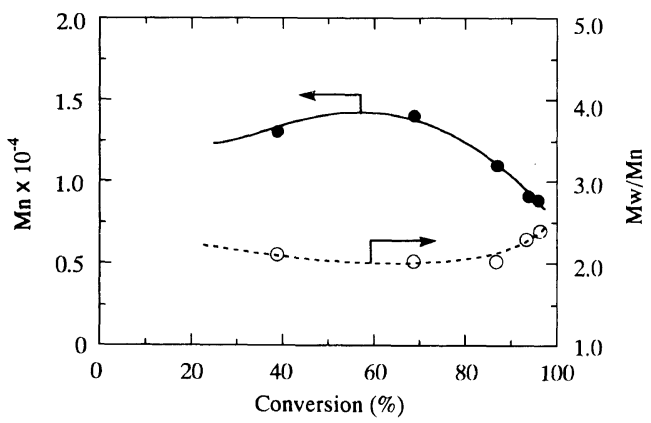

Figure 2. Plots of average molecular weight (solid line) and polydispersity (broken line) versus conversion for the polymerization of IBVE with 7 in dichloromethane: $[\mathrm{IBVE}]_{0}=1 \mathrm{M} ;[7]_{0}=10 \mathrm{mM}$. 


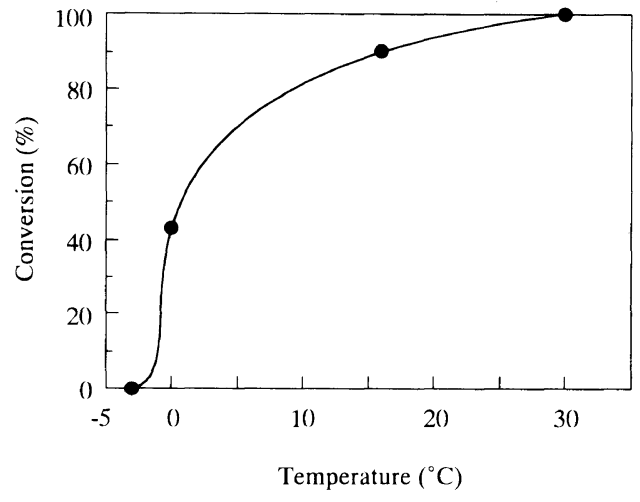

Figure 3. Temperature-conversion curve for the polymerization of IBVE with 7 in nitrobenzene for $6 \mathrm{~h}$ : $[\mathrm{IBVE}]_{0}=1 \mathrm{M} ;[7]_{0}=10 \mathrm{mM}$.

Table II. Polymerization of vinyl monomers initiated by $7^{\mathrm{a}}$

\begin{tabular}{|c|c|c|c|c|}
\hline \multirow{2}{*}{ Monomer } & Conversion $^{\mathrm{b}}$ & \multirow{2}{*}{$M_{n}^{\mathrm{c}}$} & \multirow{2}{*}{$M_{w} / M_{n}^{\mathrm{c}}$} & \multirow{2}{*}{$e$-Value ${ }^{\mathrm{d}}$} \\
\hline & $\%$ & & & \\
\hline Ethyl vinyl ether & 100 & 8100 & 2.68 & -1.17 \\
\hline$n$-Butyl vinyl ether & 100 & 4200 & 2.58 & -1.64 \\
\hline 2,3-Dihydrofuran ${ }^{\mathrm{e}}$ & 100 & 7200 & 2.10 & $-1.1^{\mathrm{f}}$ \\
\hline p-Methoxystyrene & 100 & 150000 & 1.42 & -1.11 \\
\hline Styrene & 0 & 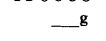 & g & -0.80 \\
\hline$N$-Vinyl carbazole ${ }^{\mathrm{e}}$ & 100 & 40000 & 2.63 & -1.34 \\
\hline
\end{tabular}

${ }^{\mathrm{a}}[7]_{0}=10 \mathrm{mM}$, $[\text { Monomer }]_{0}=1 \mathrm{M}$, in $\mathrm{PhNO}_{2}$ at $30^{\circ} \mathrm{C}$ for 2 days. ${ }^{b}$ Calculated by GC. ${ }^{c}$ Estimated by GPC based on PSt standards. ${ }^{\mathrm{d}}$ Reference 6. ${ }^{\mathrm{e}}$ Polymerization in a mixture of $\mathrm{PhNO}_{2}$ and $\mathrm{CH}_{2} \mathrm{Cl}_{2}$ $(0.5 / 4.5(\mathrm{v} / \mathrm{v}))$. ${ }^{\mathrm{f}}$ Reference $7 .{ }^{\mathrm{g}}$ Could not be determined.

The polymerization of vinyl ethers such as ethyl vinyl ether, $n$-butyl vinyl ether, and 2,3-dihydrofuran gave the corresponding poly(vinyl ether)s, respectively. $p$-Methoxystyrene was also polymerized under the same conditions to give the corresponding polymer with rather high molecular weight, although polymerization did not proceed in the case of styrene. Even at $30^{\circ} \mathrm{C}$, the polymerization of $N$-vinyl carbazole proceeded without the formation of gel products. Thus, the bis-1,3-dithiolium salt serves as an excellent cationic initiator for polymerization of various vinyl monomers with high negative $e$ values. It should be noted that this salt can be used as a cationic initiator, even above room temperature, while conventional ones generally require use below $0^{\circ} \mathrm{C}$ in the polymerization of most monomers because of the generation of oligomers. Under similar conditions in dichloromethane, no poly(IBVE) was obtained at room temperature when IBVE was treated with $\mathrm{BF}_{3} \mathrm{OEt}_{2}(1 \mathrm{~mol} \%)$, but at $0^{\circ} \mathrm{C}$ poly(IBVE) with low molecular weight $\left(M_{n}=3700\right)$ was formed.

The initiator efficiency of bis-1,3-dithiolium salt, 7 in the polymerization, was also studied. This salt shows characteristic UV absorption due to its radical cation. It manifests a maximum absorption peak at $580 \mathrm{~nm}$, at which both TTF and its dication have no absorption at all, so that the initiator efficiency could be estimated from the intensity ratio of the absorption before and after polymerization.

Figure 4 shows UV spectra before and after the polymerization of $p$-methoxystyrene by 7 in nitrobenzene at $30^{\circ} \mathrm{C}$ for 2 days. Poly ( $p$-methoxystyrene) had no absorption peak at this wave length. The UV spectrum

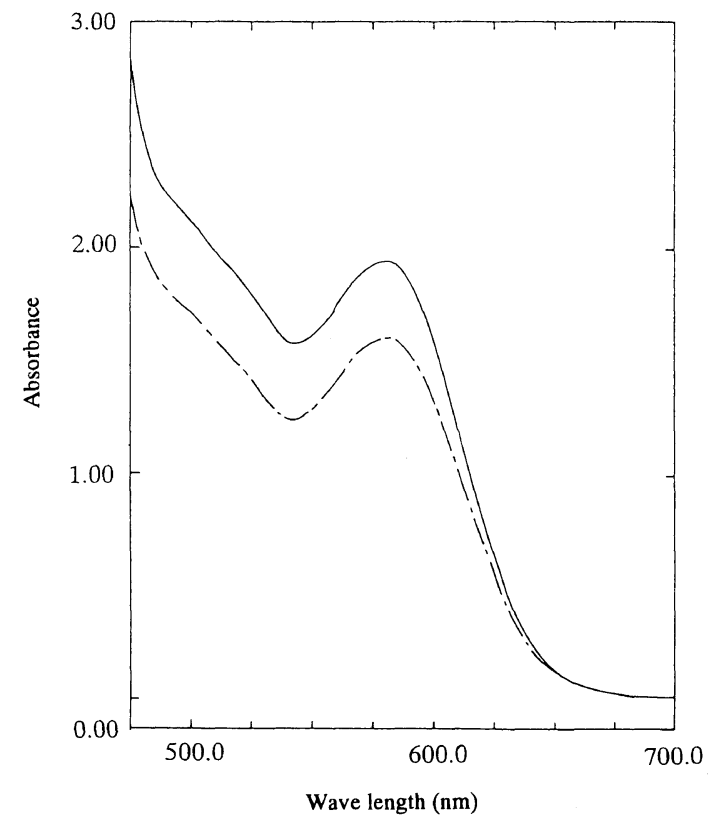

Figure 4. UV spectra of 7 before (solid line) and after (broken line) the polymerization of $p$-methoxystyrene in nitrobenzene at $30^{\circ} \mathrm{C}$ for 2 days: $[p \text {-methoxystyrene }]_{0}=1 \mathrm{M} ;[7]_{0}=10 \mathrm{mM}$.

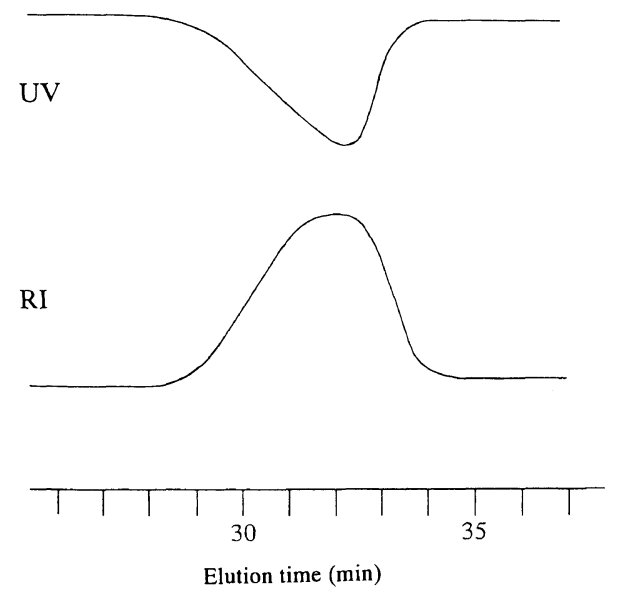

Figure 5. GPC profiles of the poly(IBVE) obtained by the polymerization with 7 in nitrobenzene at $30^{\circ} \mathrm{C}$ for $24 \mathrm{~h}$ : [IBVE] $]_{0}=1 \mathrm{M}$; $[7]_{0}=10 \mathrm{mM}$

was obtained for a freshly prepared nitrobenzene solution of 7. After being held at $60^{\circ} \mathrm{C}$ for 4 days under nitrogen, the solution was again subjected to UV spectroscopy. No difference was observed in the UV absorption spectra, indicating that no decomposition occurred. The initiator efficiency for the polymerization of $p$-methoxystyrene was estimated to be $18.7 \%$, while $2.5 \%$ in the case of the polymerization of IBVE under the same conditions. Propagation thus appears much faster than the initiation because of the low electrophilicity of 7 . The initiation mechanism above may be radical coupling via electron transfer or direct electrophilic attack of 7 on vinyl monomers. If initiation takes place by the latter mechanism, the corresponding polymer obtained is expected to exhibit UV absorption based on the vinyl group of 7.

Figure 5 shows GPC profiles of poly(IBVE) obtained by the polymerization by 7 in nitrobenzene at $30^{\circ} \mathrm{C}$ for $24 \mathrm{~h}$. The polymer actually absorbs UV; weak absorption was discerned on the higher molecular weight side. These 
results indicate that poly(IBVE) obtained by this polymerization contains a TTF moiety in the head group. It is suggested that the terminal carbon of the polymer head group combines with bis-1,3-dithiol at the 2position, when the results from reactions of electronrich olefins are taken into account, ${ }^{8}$ but this is not clear.

In conclusion, bis-1,3-dithiolium salts, the radical cation salts of TTF, were able to initiate the cationic polymerization of vinyl monomers. The polymerization of monomers with high negative $e$ proceeded efficiently using 7 to give the corresponding polymers, except for styrene. This polymerization was highly temperature dependent and the radical cation salt, 7 was suitable as the initiator for polymerization above room temperature. The polymer obtained should have a TTF moiety in its head group, although initiator efficiency was not so high. and Dr. K. Sasaki for GC analysis, and Dr. Y. Tsukahara for conducting GPC analysis with UV detection.

\section{REFERENCES AND NOTES}

1. F. Wudl, D. Wobschall, and E. J. Hufnagel, J. Am. Chem. Soc., 94, 670 (1972).

2. P. Delhaes, C. Coulon, J. Amiell, S. Flandrois, E. Toreilles, J. M. Fabre, and L. Giral, Mol. Cryst. Liq. Cryst., 50, 43 (1979).

3. N. Tokura, T. Nagai, and Y. Sonoyama, Tetrahedron Lett., 1145 (1965).

4. E. Yoshida, T. Takata, T. Endo, T. Ishizone, A. Hirao, and S. Nakahama, Chem. Lett., 1827 (1994).

5. E. Yoshida, K. Nakamura, T. Takata, and T. Endo, J. Polym. Sci., Part A, Polym. Chem., 31, 1505 (1993).

6. L. J. Young, J. Polym. Sci., Part A, Polym. Chem., 54, 411 (1961).

7. M. Furusawa, Kogyo Kagaku Zasshi, 73, 580 (1970).

8. R. W. Hoffmann, Angew. Chem., Int. Ed. Engl., 7, 754 (1968).

Acknowledgment. The author thank Dr. M. Sakai 